Original Research Article

\title{
A retrospective analysis of antibiogram on urinary isolates in a tertiary care hospital, Trivandrum, India
}

\author{
Pramodh K. ${ }^{1}$, Thansila L. T. ${ }^{2 *}$, Pushpajan K. S. ${ }^{2}$, Lallu Mariam Jacob ${ }^{3}$
}

\begin{abstract}
${ }^{1}$ Department of General
Medicine, SK Hospital, Edappazhanji, Trivandrum,

Kerala, India

${ }^{2}$ Intern, ${ }^{3}$ Department of

Pharmacy Practice, The Dale

View College of Pharmacy and

Research Centre, Punalal,

Trivandrum, Kerala, India
\end{abstract}

Received: 18 March 2019

Revised: 05 April 2019

Accepted: 03 May 2019

\section{*Correspondence to: \\ Dr. Thansila LT, \\ Email: 9037685401thansi@ \\ gmail.com}

Copyright: (C) the author(s), publisher and licensee Medip Academy. This is an openaccess article distributed under the terms of the Creative Commons Attribution NonCommercial License, which permits unrestricted noncommercial use, distribution, and reproduction in any medium, provided the original work is properly cited.

\begin{abstract}
Background: Antimicrobial resistance among bacterial strains is an emerging problem. Urinary tract infections are one of the most common bacterial infections in humans both in the hospital and the community settings. Gram-negative bacilli are the common pathogens isolated in urine. These uropathogens have developed resistance to commonly prescribed antimicrobial agents. This severely limits the effective empirical treatment options. Objective of this study was to determine the prevalence and antibiotic susceptibility patterns of bacterial uropathogens isolated from patients attending a tertiary care hospital Trivandrum.

Methods: Urine samples received for culture in the laboratory between 6 month periods was cultured in MacConkey agar and blood agar plates. The growth from urine cultures was processed for identification and antibiotic susceptibility as per standard methods. The details of urinary pathogens grown from urine samples and their Antibiogram profile were collected from the records.

Results: Out of 924 specimens investigated for significant bacteriuria, 226 shows positive cultures. E.coli and Klebsiella were the predominant pathogens isolated. Antibiotics like $3^{\text {rd }}$ generation cephalosporins, fluoroquinolones, and cotrimoxazole are the usual empirical treatment options, these organisms have developed resistance towards the latter which might make the empirical therapy less effective.

Conclusions: Gram-negative bacilli were the predominant pathogens isolated and many were resistant to the commonly prescribed antibiotics. Routine surveillance and monitoring studies need to be constantly conducted to update clinicians on the prevalent pathogens for the rational and empirical treatment of bacteriuria. Beta-lactam beta-lactamase inhibitors, aminoglycosides, carbapenem, and nitrofurantoin showed low resistance so they should be considered as empirical treatment options.
\end{abstract}

Keywords: Antibiogram, Antibiotics, Bacteriuria, Resistance, Uropathogens

\section{INTRODUCTION}

Bacteriuria is the presence of bacteria in urine. Based on the presence and absence of clinical manifestations, bacteriuria may be classified as symptomatic or asymptomatic bacteriuria. Presence of organisms like E. Coli, Klebsiella etc. may cause urinary tract infections which can be regarded as symptomatic bacteriuria. And if there are no symptoms, it's regarded as asymptomatic bacteriuria. $^{1}$

Hospital antibiogram provides a region-wide report of culture and susceptibility data. Antimicrobial sensitivity studies are conducted to determine the sensitivity of organisms towards antibiotics. These studies are important because of the increased rate of antibiotic resistance. Antibiotic resistance makes it difficult to treat infections 
caused by bacteria. It makes the surveillance of antimicrobial sensitivity essential. Additionally, trends in the appropriateness of antibiotic prescribing were also assessed. $^{2}$

The aim of this study is to determine the prevalence and antimicrobial sensitivity patterns of uropathogens in a tertiary care hospital because these are two factors which can help in improving the efficacy of empirical therapy.

\section{Aim and objectives}

- To study the prevalence of various bacterial isolates present in the urinary culture samples.

- To study the changing trends in the susceptibility patterns of uropathogens isolated over a 6 months period.

- To assess the prevalence of multidrug resistance among the urinary isolates.

\section{METHODS}

\section{Inclusion criteria}

- $\quad$ Patients admitted for more than 3 days

- Both genders

- $\quad$ Age $>18$ years

\section{Exclusion criteria}

- Pregnant women

- Nursing mothers

- Mentally retarded

- Paediatrics

- OP patients

\section{Study Period}

The study has been carried out for 6 months from September 2018 to February 2019.

\section{Study population}

The study population consists of 924 urine specimens. The patients were selected on the basis of inclusion-exclusion criteria.

A retrospective observational study was carried out for a 6 month period in 924 urine specimens to determine the susceptibility and resistance of gram negative organisms towards the existing empirical treatment options.

\section{Statistical analysis}

For the evaluation of the study data descriptive quantitative type statistical analysis was used. Data from laboratory investigation was entered into the Microsoft Excel Spreadsheet.

\section{Study design}

A retrospective analysis of urine culture was performed at a microbiology laboratory in a tertiary care hospital, Trivandrum. The age, gender, urine culture reports, and their antibiogram profile were collected from the registration records using a standard data collection form. Data analysis was done using Excel.

\section{Identification of isolate}

According to standard operating procedures, urine samples were cultured on to MacConkey agar and blood agar plates, then incubated at $37^{\circ} \mathrm{C}$ for 24 hours and the colonies were identified based on the bacterial morphology.

\section{Anti-microbial susceptibility tests}

Urine isolates were selected to determine their susceptibility patterns against the first line antimicrobial agents by the disc diffusion method. The antimicrobial agents used were amoxiclav $(30 \mu \mathrm{g})$, gentamicin $(120 \mu \mathrm{g})$, amikacin $(30 \mu \mathrm{g})$, cefuroxime $(30 \mu \mathrm{g})$, cefixime $(5 \mu \mathrm{g})$, ceftriaxone $(30 \mu \mathrm{g})$, ceftazidime $(30 \mu \mathrm{g})$, cefepime $(30 \mu \mathrm{g})$, cefoperazone sulbactam $(75 / 30 \mu \mathrm{g})$, doxycycline (30 $\mu \mathrm{g})$, tigecycline $(15 \mu \mathrm{g})$, levofloxacin $(5 \mu \mathrm{g})$, ciprofloxacin $(5 \mu \mathrm{g})$, piperacillin-tazobactam $(100 / 10 \mu \mathrm{g})$, imipenem $(10 \mu \mathrm{g})$, nitrofurantoin $(100 \mu \mathrm{g})$, cotrimoxazole (25 $\mu \mathrm{g})$, nalidixic acid $(30 \mu \mathrm{g})$, linezolid $(10 \mu \mathrm{g})$, tetracycline $(30 \mu \mathrm{g})$, vancomycin $(30 \mu \mathrm{g})$, clindamycin (2 $\mu \mathrm{g})$, Teicoplanin(30 $\mu \mathrm{g})$, Tigecycline $(15 \mu \mathrm{g})$, and Penicillin (1 unit).

\section{RESULTS}

Out of 924 urine specimens screened for significant bacteriuria, a total of 226 showed positive culture. In 226 bacterial isolates, $57 \%$ were from female patients and $43 \%$ from male patients. Among 226 urine isolates, gramnegative constitutes $221(97.78 \%)$ and gram-positive constitutes $5(2.21 \%)$. Figure 1 shows the distribution of bacteria among urine isolates $(n=226)$.

The prevalence of bacterial isolate from urine culture was E. coli (47.3\%), followed by Klebsiella (27.8\%), Pseudomonas (7.96\%), Enterobacter (6.19\%), Citrobacter (5.75\%), Acinetobacter spp. (2.65\%), $\beta$ streptococcus $(1.76 \%)$ and $S$. aureus $(0.44 \%)$ is shown in Figure 1. Antibiogram of E. coli and Klebsiella are shown in Figure 2 and Figure 3 respectively.

Antibiogram of $E$. coli showed higher resistance towards nalidixic acid $(78.5 \%)$ followed by cefuroxime $(75.7 \%)$, cefixime $(71.9 \%)$, ceftriaxone and amoxyclav $(68.2 \%)$ levofloxacin (62.6\%), ciprofloxacin $(59.8 \%)$, cefepime (56\%) doxycycline $(51.4 \%)$. Piperacillin tazobactam $(82.2 \%)$ showed higher susceptibility followed by cefperazone sulbactam $(79.4 \%)$, nitrofurantoin $(72.8 \%)$, and imipenem $(60.7 \%)$ and gentamicin $(53.2 \%)$. 


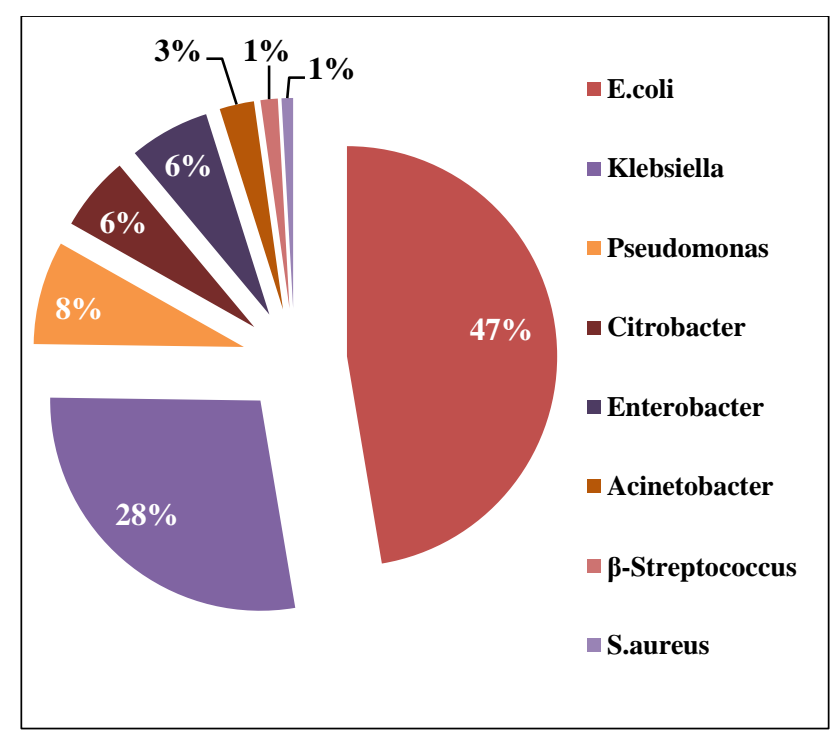

Figure 1: Distribution of bacteria among urine isolates $(n=226)$.

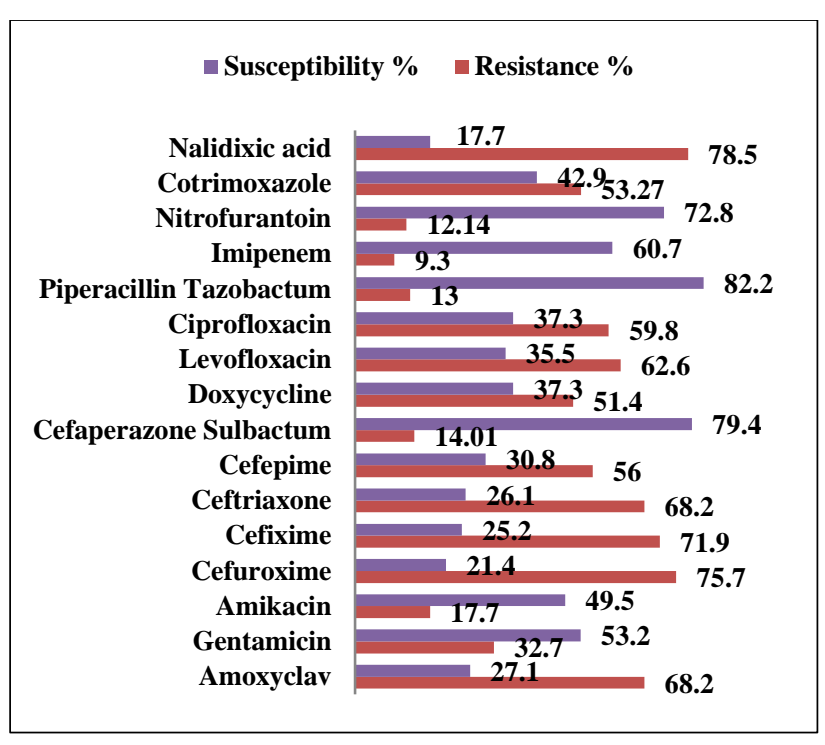

Figure 2: Antibiogram of E. coli.

Table 1: Antimicrobial resistance patterns of other urinary isolates.

\begin{tabular}{|c|c|c|c|c|c|c|}
\hline Antibiotics & $\begin{array}{l}\text { Pseudomonas } \\
\text { (18)* }\end{array}$ & $\begin{array}{l}\text { Citrobacter } \\
(13)^{*}\end{array}$ & $\begin{array}{l}\text { Enterococci } \\
(14) *\end{array}$ & $\begin{array}{l}\text { Acinetobacter } \\
(6) *\end{array}$ & $\begin{array}{l}\text { Bstreptococci } \\
(4) *\end{array}$ & $\begin{array}{l}\text { S. aureus } \\
\text { (1)* }\end{array}$ \\
\hline Amoxyclav & & $7(53.8 \%)$ & $3(21.4 \%)$ & $3(50 \%)$ & & \\
\hline Gentamicin & $7(38.8 \%)$ & $4(22.2 \%)$ & $7(50 \%)$ & $2(33.3 \%)$ & $1(25 \%)$ & \\
\hline Amikacin & $6(33.3 \%)$ & $1(7.6 \%)$ & $6(42.8 \%)$ & $2(33.3 \%)$ & $1(25 \%)$ & \\
\hline Cefuroxime & $1(5.5 \%)$ & $10(76.9 \%)$ & $6(42.8 \%)$ & $4(66.6 \%)$ & & \\
\hline Cefipime & & $10(76.9 \%)$ & $6(42.8 \%)$ & $4(66.6 \%)$ & & \\
\hline Ceftriaxone & & $9(69.23 \%)$ & $5(35.7 \%)$ & $3(50 \%)$ & & \\
\hline Cefepime & $3(16.6 \%)$ & $6(46.1 \%)$ & $3(21.4 \%)$ & $3(50 \%)$ & & \\
\hline $\begin{array}{l}\text { Cefperaxone } \\
\text { Sulbactum }\end{array}$ & $2(11.1 \%)$ & $1(7.6 \%)$ & $1(7.14 \%)$ & & & \\
\hline Doxycycline & $5(27.7 \%)$ & $5(38.4 \%)$ & $2(14.28 \%)$ & $3(50 \%)$ & & \\
\hline Levofloxacin & $4(22.2 \%)$ & $4(22.2 \%)$ & $5(35.7 \%)$ & $3(50 \%)$ & $3(75 \%)$ & 1 \\
\hline Ciprofloxacin & $3(16.6 \%)$ & $4(22.2 \%)$ & $5(35.7 \%)$ & $3(50 \%)$ & $3(75 \%)$ & 1 \\
\hline $\begin{array}{l}\text { Piperacillin } \\
\text { Tazobactum }\end{array}$ & & $1(7.6 \%)$ & $1(7.14 \%)$ & $1(16.6 \%)$ & & \\
\hline Imipinem & $6(33.3 \%)$ & & & & & \\
\hline Nitrofurantoin & $1(5.5 \%)$ & $2(15.3 \%)$ & $3(21.4 \%)$ & $5(83.3 \%)$ & & \\
\hline Cotrimoxazole & & $4(22.2 \%)$ & $5(35.7 \%)$ & $2(33.3 \%)$ & $1(25 \%)$ & \\
\hline Nalidixic acid & & $11(84.6 \%)$ & $7(50 \%)$ & $3(50 \%)$ & $1(25 \%)$ & 1 \\
\hline Tetracycline & & & & & $2(50 \%)$ & \\
\hline Clindamycin & & & & & $3(75 \%)$ & \\
\hline Cefazolin & $1(5.5 \%)$ & & & & & \\
\hline
\end{tabular}

*Indicate total number of organism

Klebsiella antibiogram showed greater susceptibility towards imipenem (60.3\%), gentamicin (55.5\%), piperacillin sulbactam $(53.9 \%)$, cefperazone sulbactam (52.3\%) amikacin (50.7\%), cefepime (38.0\%), ciprofloxacin $(36.5 \%)$, levofloxacin $(31.7 \%)$. Resistance pattern shows higher resistance to cefuroxime $(71.4 \%)$, cefexime $(68.2 \%)$, levofloxacin $(61.9 \%)$, ciprofloxacin and nalidixic acid (60.3\%), doxycycline (58.7\%) cotrimozaxole and amoxyclav $(57.1 \%)$, nitrofurantoin $(53.9 \%)$. 


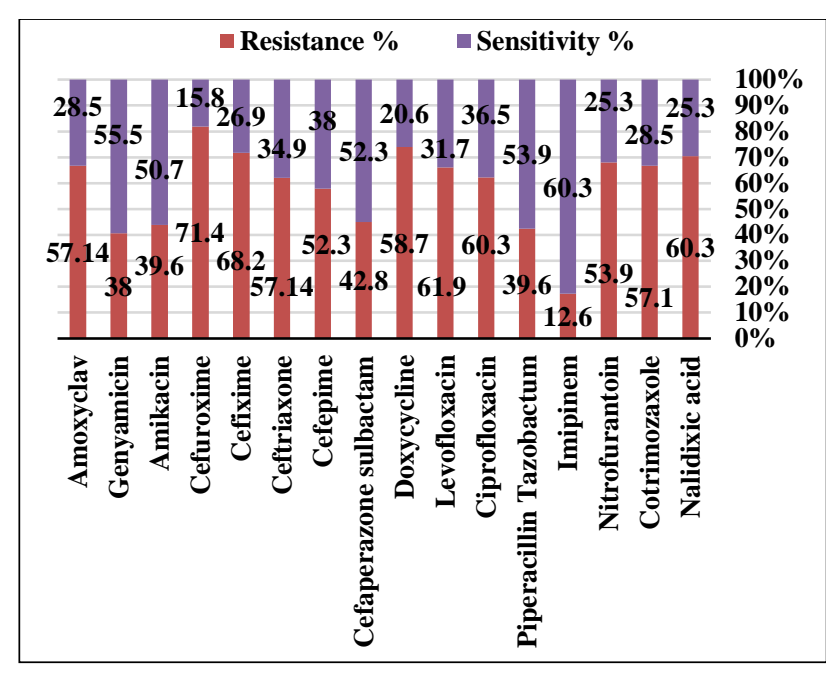

Figure 3: Antibiogram of Klebsiella.

Pseudomonas and Citrobacter contributed $7.96 \%$ and $5.75 \%$ of the total urinary isolates. Pseudomonas showed $38.8 \%$ resistance towards gentamicin, $33.3 \%$ resistance to amikacin and imipenem. Citrobacter showed $84.6 \%$ resistance towards nalidixic acid, $76.9 \%$ resistance towards cefuroxime and cefepime, $69.23 \%$ resistance towards ceftriaxone. Enterobacter showed 50\% resistance towards gentamicin and nalidixic acid, $42.8 \%$ resistance towards amikacin, cefuroxime and cefepime. These isolates showed more sensitivity towards Cefoperazone sulbactam followed by piperacillin-tazobactam. Enterococci showed more sensitivity towards Gentamicin. The antimicrobial resistance pattern of organisms other than E. coli and Klebsiella is shown in Table 1.

\section{DISCUSSION}

Antibiotic susceptibility or resistance pattern of uropathogens have been changing over the years. One of the important factors contributing to the high resistance rates may be due to the increasing use of antibiotics without knowing the causative organism and its susceptibility pattern towards the antibiotics.

A total of 226 positive culture and sensitivity report during a 6 month period were analysed in this study. In this study, significant bacteriuria accounted for $25 \%$. It was lower to the isolation rate reported by some other studies. ${ }^{3-5}$ The prevalence was more in females $129(57 \%)$ as compared to males 97 (43\%), this was in agreement with other studies by Razak SK et al, and Bency JAT. ${ }^{3,6}$ In the present study, E. coli and Klebsiella were the frequently isolated uropathogens as similar to other studies. ${ }^{3,7,8}$

In our study, E. coli was most resistant to Nalidixic acid followed by cefuroxime, cefixime, and amoxiclav. It was most sensitive to Piperacillin tazobactam, followed by cefoperazone sulbactam, nitrofurantoin, and imipenem. Present antibiogram shows E.coli sensitivity towards Piperacillin tazobactam in $83 \%$ cases, while sensitivity to Cefoperazone Sulbactam is $80 \%$, nitrofurantoin is $73 \%$ and imipenem is $61 \%$, which was in accordance to study conducted by Jha A et al. ${ }^{9}$ Sensitivity towards cephalosporins is very low as compared to other studies. ${ }^{10,11}$ This difference occurs due to the indiscriminate use of cephalosporins. As a result, present antibiogram results favor the use of piperacillintazobactam or cefoperazone sulbactam as the drug of choice.

Isolates of $K$. Pneumonia were sensitive to Imipenem, Gentamicin, followed by piperacillin-tazobactam, Cefoperazone sulbactam, Amikacin, and some secondgeneration cephalosporins. ${ }^{3,6,7}$

The Pseudomonas and Enterococci were resistant to gentamicin and amikacin. Isolates of Acinetobacter and Citrobacter were sensitive to Cefoperazone sulbactam and Imipenem. ${ }^{12}$

Antimicrobial resistance may be inherent and it may be due to the natural biological response of microbes to the antimicrobial drugs. ${ }^{13}$

\section{CONCLUSION}

This study provides information on the antibiotic resistance pattern of urinary isolates which may be a helpful guide for physicians to initiate empiric therapy and in the formulation of hospital antibiotic policy. E.coli was the most prevalent urinary isolate followed by Klebsiella, Pseudomonas, Citrobacter, and other species.

Third generation cephalosporins, fluoroquinolones, and cotrimoxazole are the most common empirical treatment options against gram-negative bacilli. Over the years these uropathogens have developed resistance towards the usual empirical treatment options. Further advanced research studies are required to formulate cautionary guidelines to prevent the development of antibiotic resistance otherwise development of multi-drug resistant bacteria will become a major threat to the health care system and the usual empirical treatment options will no longer be effective.

\section{ACKNOWLEDGEMENTS}

Authors would like to extend their heartfelt thanks to the staffs in the Microbiology Department of SK Hospital and our batch mates who extended their support.

Funding: No funding sources

Conflict of interest: None declared

Ethical approval: Not required

\section{REFERENCES}

1. Chander A, Shrestha CD. Prevalence of extendedspectrum beta-lactamase producing Escherichia coli and Klebsiella pneumoniae urinary isolates in a tertiary care hospital in Kathmandu, Nepal. BMC Res Notes 2013;6:487. 
2. Sarasu VP, Rani SR. Bacteriological profile and antibiogram of urinary tract infections at a tertiary care hospital. Int $\mathbf{J}$ Med Microbiol Trop Dis. 2017;3(3):106-12.

3. Razak SK, Gurushantappa V. Bacteriology of urinary tract infection and antibiotic susceptibility pattern in a tertiary care hospital in South India. Int $\mathbf{J}$ Med Sci Public Health. 2012;1(2):109-12.

4. Das RN, Chandrashekhar TS, Joshi HS, Gurung M, Shrestha N, Shivananda PG. Frequency and susceptibility profile of pathogens causing urinary tract infections at a tertiary care hospital in western Nepal. Singapore Med J. 2006 Apr;47(4):281-5.

5. Shah LJ, Vaghela GM, Mahida H. Urinary tract infection: Bacteriological profile and its antibiotic susceptibility in Western India. Nat J Med Res. 2015;5(1):71-4.

6. Priyanka R, Jose P. A study on the bacteriological profile of urinary tract infection in adults and their antibiotic sensitivity pattern in a tertiary care hospital in central Kerala, India. Int J Res Med Sci. 2017 Jan 23;5:666-9.

7. Prakasam AK, Kumar KD, Vijayan M. A cross sectional study on distribution of urinary tract infection and their antibiotic utilisation pattern in Kerala. Int J PharmTech Res. 2012;4(3):1310-6.

8. Sood S, Gupta R. Antibiotic resistance pattern of community acquired uropathogens at a tertiary care hospital in Jaipur, Rajasthan. Indian $\mathbf{J}$ Community Med. 2012;37(1):39-44.
9. Jha A, Agrawal M, Neral A, Hishikar R, Mahesh B. Escherichia coli as uropathogen: antibiotic susceptibility profiling. Int J Basic Clin Pharmacol. 2018;7(2):433-8.

10. Fluit AC, Jones ME, Schmitz FJ, Acar J, Gupta R, Verhoef J. Antimicrobial resistance among urinary tract infection (UTI) isolates in Europe: results from the SENTRY Antimicrobial Surveillance Program 1997. Antonie Van Leeuwenhoek. 2000;77(2):14752.

11. Akhtar N, Rahman R, Sultana S. Antimicrobial sensitivity pattern of Escherichia coli causing urinary tract infection in Bangladeshi patients. Am J Microbiol Res. 2016;4(4):122-5.

12. 12. Magdaline J. Changing trends in the Antibiotic susceptibility pattern of Acinetobacter species isolated from clinical specimens over a period of five years from a tertiary care hospital. J Med Scie Cli Resea. 2017;05(06):24144-7.

13. Khalil A. Prevalence and antibiogram of uncomplicated lower urinary tract infections in human population of Gilgit, Northern Areas of Pakistan. Pak J Zool. 2008 Aug 1;40(4):295-301.

Cite this article as: Pramodh $\mathrm{K}$, Thansila LT, Pushpajan KS, Lallu JM. A retrospective analysis of antibiogram on urinary isolates in a tertiary care hospital, Trivandrum, India. Int J Basic Clin Pharmacol 2019;8:1273-7. 